\title{
Selective Hydrogenation by Carbocatalyst: The Role of Radicals
}

\author{
Muhammad Sohail Ahmad, ${ }^{\dagger}$ Huixin He, ${ }^{\S}$ Yuta Nishina*†:
}

†Graduate School of Natural Science and Technology, Okayama University, 3-1-1 Tsushimanaka, Kita-ku, Okayama 700-8530, Japan

§Department of Chemistry, Rutgers, the State University of New Jersey, Newark, NJ, 07102, USA

†Research Core for Interdisciplinary Sciences, Okayama University, 3-1-1 Tsushimanaka, Kita-ku, Okayama 7008530, Japan

\section{Table of Contents}

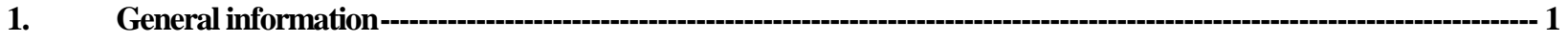

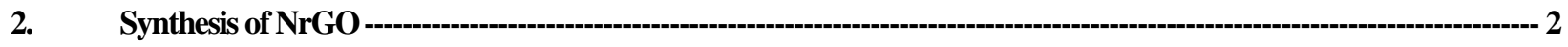

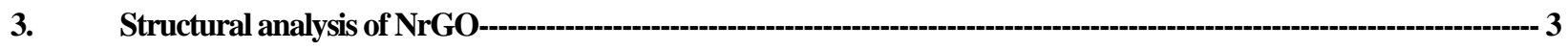

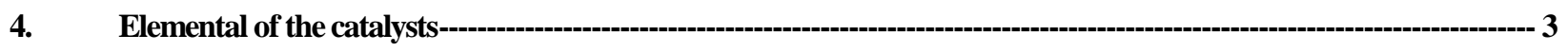

5. General procedure for the hydrogenation of nitroarenes -

6. General procedure for the hydrogenation of ketones---1--

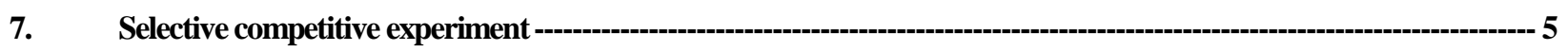

8. Representive procedure for the hydrogenation of nitroarenes -

9. Product identification ---

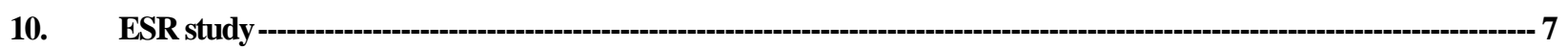

11. Spin trap experiment - 7

12. Method for the recyclability test

13. Screening test-- 9

14. Proposed reaction pathway ---on

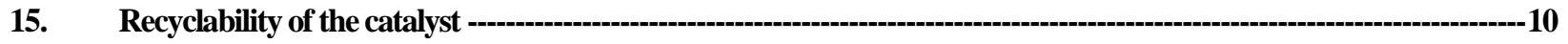

16. ${ }^{1} \mathrm{H}$ nmr spectral charts of the aniline derivatives---12

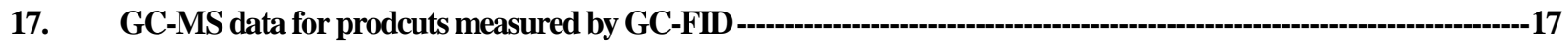

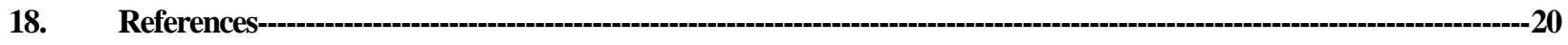

\section{General Information}

All the chemicals used in this study were purchased from commercial sources and used as received unless otherwise mentioned. The surface chemistry and elemental analyses of the catalysts were performed using an X-ray photoelectron spectroscopy (XPS; JPS-9030) with a pass energy of $20 \mathrm{eV}$. The morphology of NrGO was measured using transmission electron microscopy (TEM; JEOL JEM-2100F), and the functional groups on the surface of the catalysts were recorded by Fourier-transform infrared spectrometry (FT-IR; Shimadzu IR Tracer 100). The samples for the FT-IR were dried and mixed with $\mathrm{KBr}$, and then pressed into $1.3 \mathrm{~cm}$-diameter pellets. Freeze-drying of the 
catalysts was performed using ADVANTEC DRZ350WC. ESR analysis was performed using an electron spin resonance spectrometer (JES-X310) with microwave frequency $=9.542 \mathrm{GHz}$, modulation frequency $=100 \mathrm{kHz}$, power $=1 \mathrm{~mW}$, and weep time $=2 \mathrm{~min}$. The products were quantified by gas chromatography (GC; Shimadzu GC-2014), equipped with a flame ionization detector (FID) or ${ }^{1} \mathrm{H}$ NMR using 1,1,2,2-tetrachloroethane as an internal standard. Nuclear magnetic resonance (NMR) spectroscopy was measured by Varian 400-MR.

\section{Synthesis of NrGO}

Generally, graphite powder $(100 \mathrm{~g})$ was dispersed in $2.5 \mathrm{~L}$ of concentrated $\mathrm{H}_{2} \mathrm{SO}_{4}$. After cooling the mixture in an ice bath, $\mathrm{KMnO}_{4}(300 \mathrm{~g})$ was subsequently added and kept below $55{ }^{\circ} \mathrm{C}$. The mixture was stirred at $35{ }^{\circ} \mathrm{C}$ for $2 \mathrm{~h}$ to complete the oxidation. The generated suspension was once again cooled down, after which $5 \mathrm{~L}$ of deionized water was added slowly as the temperature was adjusted below $50{ }^{\circ} \mathrm{C}$ with continuous stirring. Then, $250 \mathrm{~mL}$ of $\mathrm{H}_{2} \mathrm{O}_{2}$ (30\% aq.) was added to the mixture. Finally, the generated brown crude graphite oxide was purified by centrifugation (10 times) to afford graphene oxide (GO). Nitrogen doping onto GO was conducted by dissolving $1 \mathrm{~g}$ of nitrogen source (guanidine carbonate) (Scheme SI 1) in $100 \mathrm{~mL}$ of $0.1 \mathrm{wt} \% \mathrm{GO}$ solution to attain a 10:1 ratio of nitrogen source to GO. The mixture was transferred into a steel-based autoclave and subjected to hydrothermal treatment at $180{ }^{\circ} \mathrm{C}$ for $8 \mathrm{~h}$. The autoclave was then allowed to cool down to room temperature naturally, after which the black precipitate was filtered and washed five times with deionized water and once with isopropanol. Finally, the product was dried in a freeze drier and labeled as $\mathrm{NrGO}$, as presented in the scheme below (Scheme SI 1). For comparison, rGO was prepared according to the same method, without the addition of a nitrogen source.

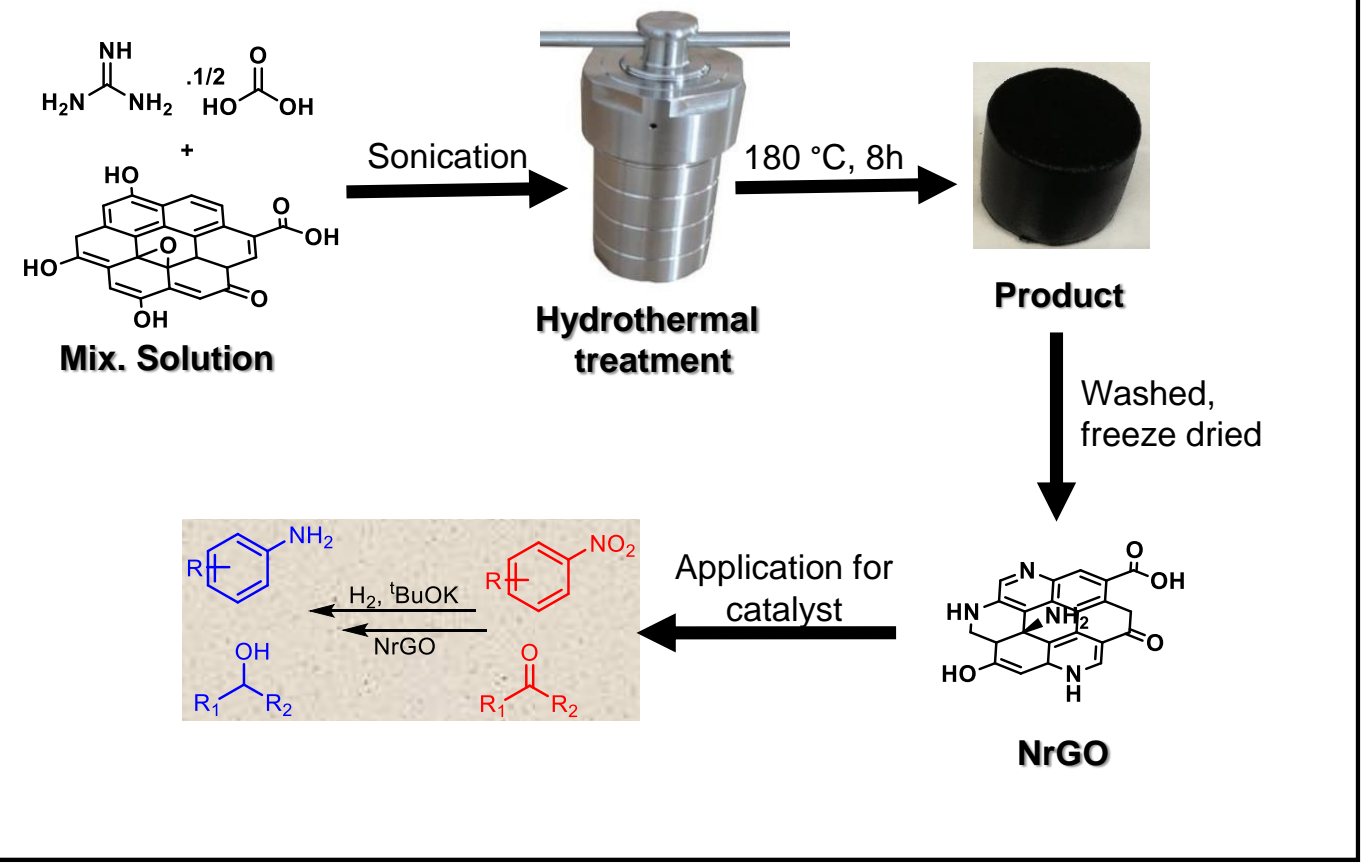

Scheme S1: Schematic illustration of the synthesis of $\mathrm{NrGO}$ and its application in catalysis. 


\section{Structural analysis of NrGO}

For the structural analysis of NrGO, we performed Fourier-transform infrared (FT-IR) spectroscopy (Figure S1a). A peak was observed at $3408 \mathrm{~cm}^{-1}$, corresponding to $-\mathrm{OH}$ and/or $-\mathrm{NH}$. The characteristic peaks at 1660 and $1548 \mathrm{~cm}^{-1}$ were assigned to the $\mathrm{C}=\mathrm{O}$ and $\mathrm{C}=\mathrm{C}$ stretching vibrations, respectively. Furthermore, the sharp peak at $1151 \mathrm{~cm}^{-1}$ may be attributed to $\mathrm{C}-\mathrm{N}$ bond stretching. ${ }^{1-3}$ The chemical composition was further examined by X-ray photoelectron spectroscopy (XPS). The XPS spectra showed peaks at 285, 400, and $532 \mathrm{eV}$, corresponding to the binding energies of $\mathrm{C} 1 \mathrm{~s}, \mathrm{~N} 1 \mathrm{~s}$, and $\mathrm{O} 1 \mathrm{~s}$, respectively (Figure SI 2). ${ }^{4,5}$ These results confirmed that the nitrogen atom was successfully doped on the graphene framework. Narrow XPS analysis at the N1s region showed a total nitrogen doping level of 5 at $\%$, with $\mathrm{NH}$ groups mainly formed (Figure $\mathrm{S} 1 \mathrm{~b}$ ). The morphology studies of NrGO using scanning electron microscopy (SEM) and transmission electron microscopy (TEM) revealed a layered structure, as reported by Gao et al. (Figure S1c and 1d). ${ }^{6}$
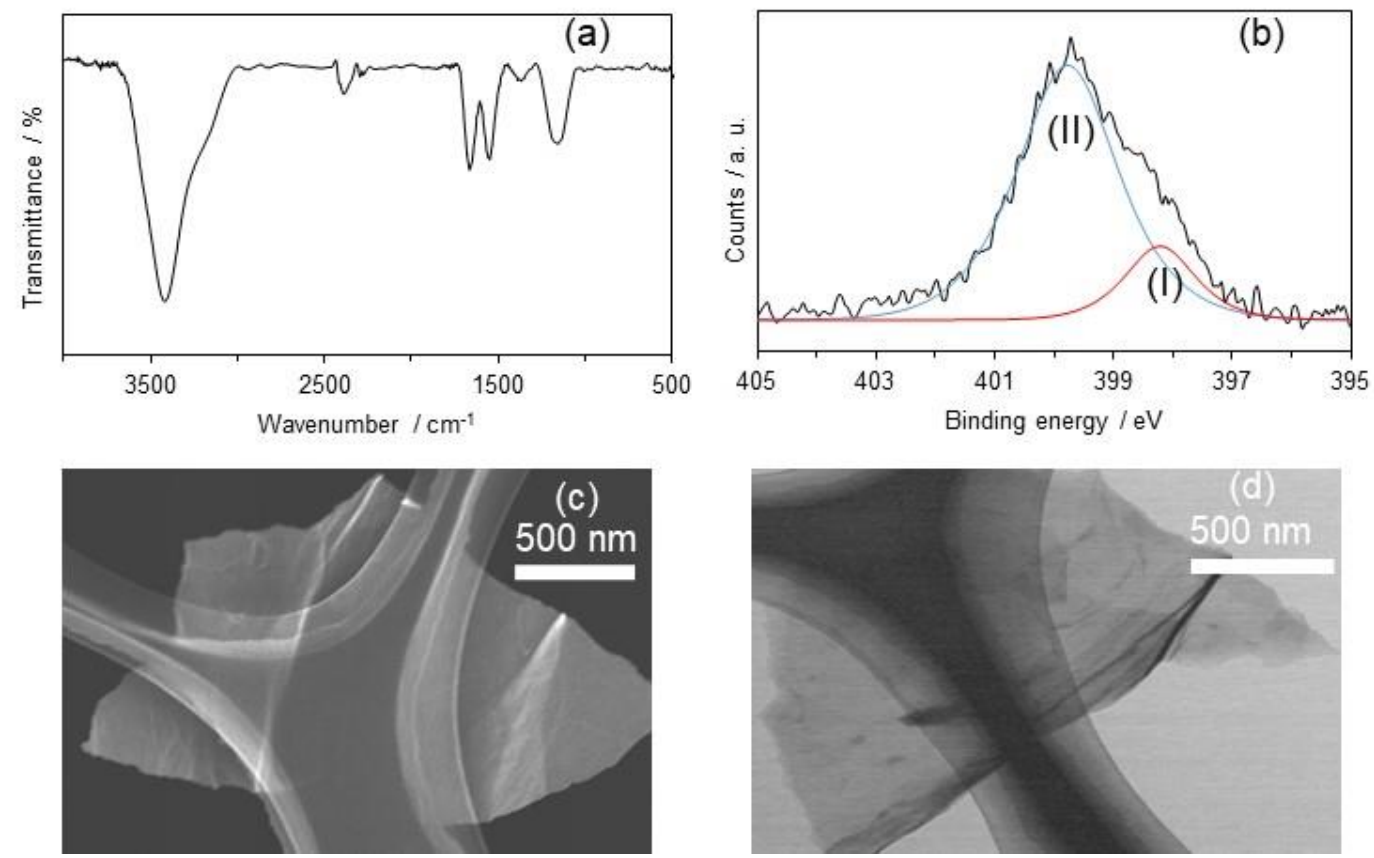

Figure S1. Structural analysis of NrGO. (a) FT-IR spectra; (b) XPS N1s spectra: (I) pyridinic and (II) NH groups detected; (c) SEM and (d) TEM images.

\section{Elemental of the catalysts}

Table S1: Elemental composition of the catalysts. ${ }^{[a]}$

\begin{tabular}{|c|c|c|c|}
\hline & $\mathrm{C} /$ at \% & $\mathrm{N} /$ at \% & O / at \% \\
\hline NrGO & 83.3 & 5.0 & 11.7 \\
\hline rGO & 85.1 & -- & 14.9 \\
\hline GO & 65.3 & -- & 34.7 \\
\hline
\end{tabular}

${ }^{\text {[a] }}$ The atomic ratio was determined by XPS. 

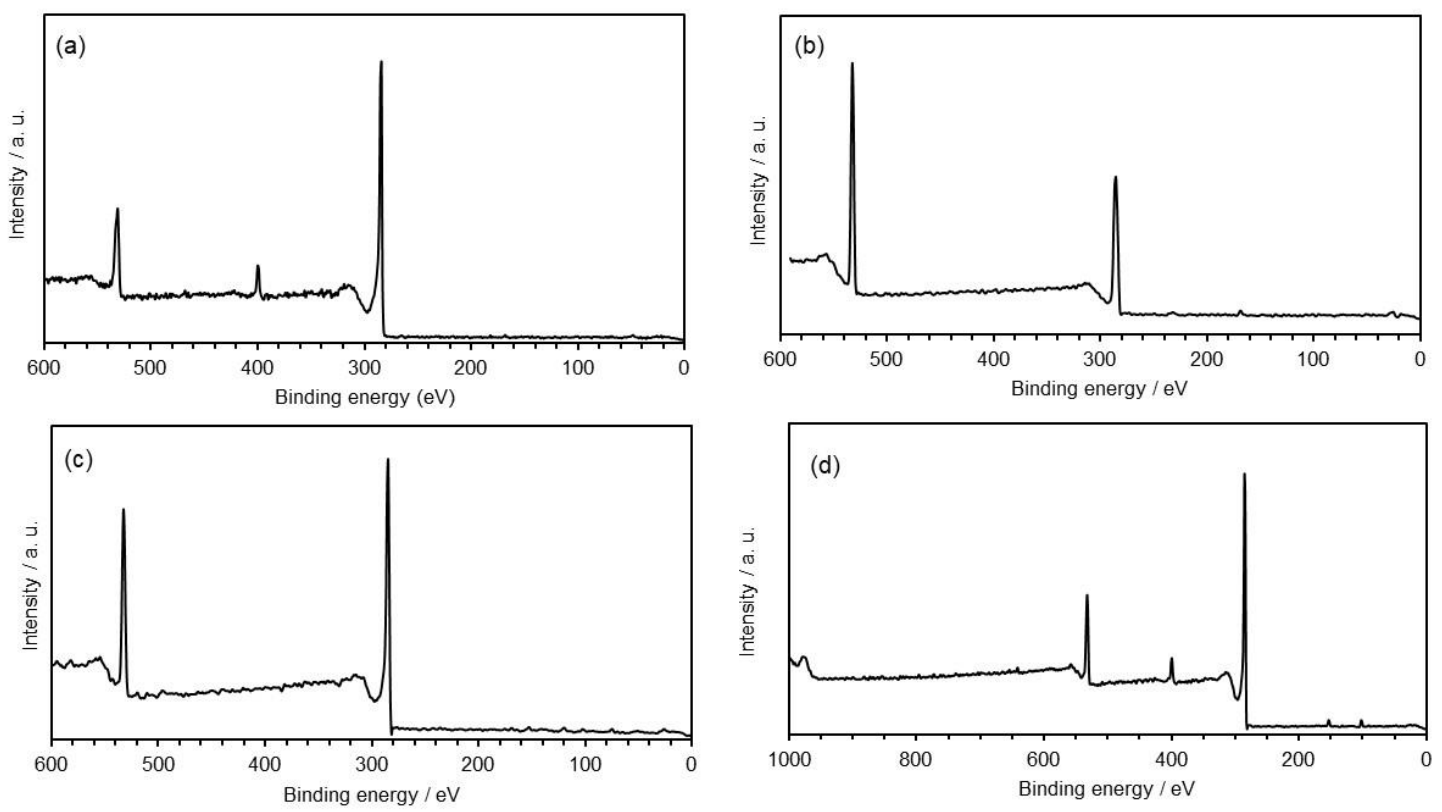

Figure S2: XPS survey spectra of (a) NrGO, (b) GO, (c) rGO, and (d) wide range XPS of NrGO

\section{General procedure for the hydrogenation of nitroarenes}

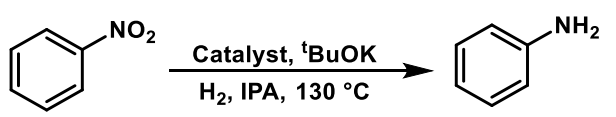

Nitroarenes $(0.5 \mathrm{mmol})$, catalyst $(20 \mathrm{mg})$, base $(1.0 \mathrm{mmol})$, solvent $(4 \mathrm{~mL})$, and $\mathrm{H}_{2}(1.5 \mathrm{MPa})$ were loaded into a glass tube equipped in a steel-based autoclave. The mixture was heated to $130{ }^{\circ} \mathrm{C}$ with continuous stirring for $2 \mathrm{~h}$, unless otherwise specified. After completion of the reaction, the mixture was cooled to room temperature. Furthermore, $0.5 \mathrm{mmol}$ of dodecane, which was used as an internal standard, was added. The product was analyzed by GC-MS and quantified by GC.

\section{General procedure for the hydrogenation of ketones}

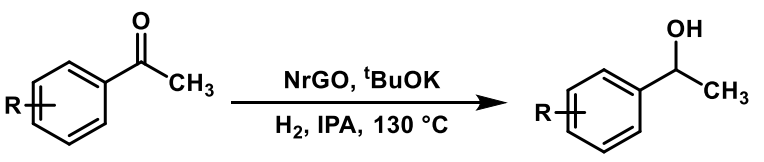

The method is similar to the one presented above for the hydrogenation of nitroarenes. A steel-based autoclave was charged with $\mathrm{NrGO}(20 \mathrm{mg})$, ketone $(0.5 \mathrm{mmol})$, base $(1.0 \mathrm{mmol})$, and solvent $(4 \mathrm{~mL})$. The autoclave was purged with $\mathrm{H}_{2}(1.5 \mathrm{MPa}) 3$ times. The mixture was then stirred at $130{ }^{\circ} \mathrm{C}$ for the specified amount of time. After completion of the reaction run, the mixture was cooled down to room temperature and $0.5 \mathrm{mmol}$ of dodecane was subsequently added and used as an internal standard. The product was analyzed by GC-MS and quantified by ${ }^{1} \mathrm{H}$ NMR. 


\section{Selective competitive experiment}

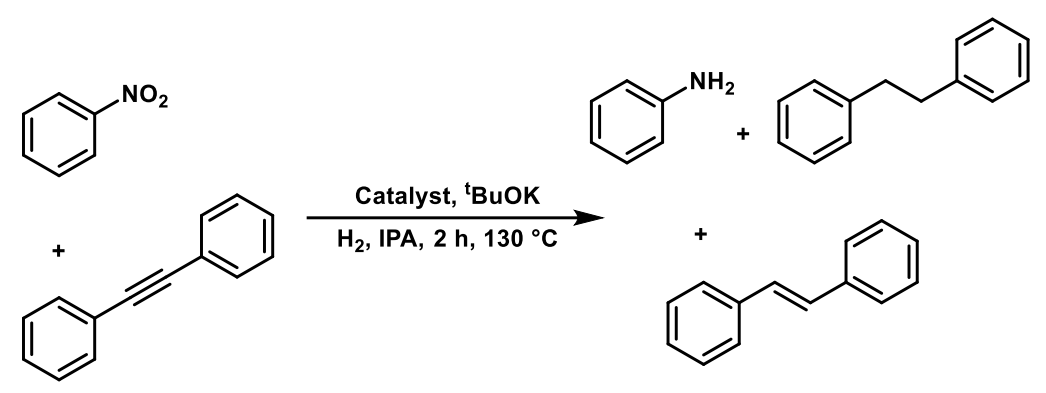

An equimolar mixture of nitrobenzene $(0.5 \mathrm{mmol})$ and diphenylacetylene $(0.5 \mathrm{mmol})$ was added into an autoclave, followed by the addition of $\mathrm{NrGO}(20 \mathrm{mg})$, IPA $(4 \mathrm{~mL})$, and ${ }^{\mathrm{t}} \mathrm{BuOK}(1 \mathrm{mmol})$. The autoclave was then pressurized with $\mathrm{H}_{2}$ to $1.5 \mathrm{MPa}$. The mixture was stirred continuously at $130{ }^{\circ} \mathrm{C}$ for a specified time. After cooling down to room temperature and releasing the hydrogen pressure in a fume hood, and $0.5 \mathrm{mmol}$ of dodecane as an internal standard was subsequently added. The product was analyzed by GC-MS and quantified by ${ }^{1} \mathrm{H}$ NMR. The same experiment was performed under $\mathrm{Pd} / \mathrm{C}$ catalyst, and the product yields were compared (see Table 5 in the manuscript).

\section{Representative procedure}

The stainless-steel auto cleave $(30 \mathrm{~mL})$ fitted with inner glass tube was charged with nitrobenzene (1 $\mathrm{mmol})$, catalyst $(40 \mathrm{mg})$, base $(2.0 \mathrm{mmol})$, solvent $(8 \mathrm{~mL})$, and $\mathrm{H}_{2}(3 \mathrm{MPa})$. The mixture was heated to $130{ }^{\circ} \mathrm{C}$ with continuous stirring for $2 \mathrm{~h}$. After completion of the reaction, the mixture was cooled to room temperature. Furtheremore, the catalyst ( $\mathrm{NrGO}$ ) was removed by filtration, and the filtrate w as extracted with ethylacetate, and concentrated under reduced pressure. The residue was purified by flash column chromatography on silica gel (hexane: ethyl acetate $=10: 1)$, to afford the product $2 \mathrm{a}$ in $84 \%$ yield $(78.2 \mathrm{mg}$ ).

\section{Product identification}

Hydrogenation of nitroarenes was performed in $30 \mathrm{ml}$ of stainless autoclave fitted with an inner glass tube. Upon completion of reaction run, the catalyst $(\mathrm{NrGO})$ was removed by filtration, and the filtrate was extracted with ethyl acetate. Evaporation of solvent followed by column chromatography, the purity of the compound was determined by ${ }^{1} \mathrm{H}$ NMR analysis. All of these compounds are known and in good agreement with the reported literature. All these compounds are known compounds and were characterized by comparison of their spectra with the reported data.

Aniline (2a): Purification by flash chromatography (hexane: ethyl acetate $=10: 1)$ gave $80 \%(43.5 \mathrm{mg}$ ) of a colorless oil. ${ }^{1} \mathrm{H}$ NMR (400 MHz, $\mathrm{CDCl}_{3}$ ): $\delta$ 7.19-7.15 (m, 2H), 6.80-6.76 (m, 1H), 6.71-6.69 (m, 2H), 3.48 (br $\left.\mathrm{s}, 2 \mathrm{H},-\mathrm{NH}_{2}\right)^{7}$ 
4-Aminoanisole (2b): Purification by flash chromatography (hexane: ethyl acetate $=10: 1)$ gave $72 \%$ (44.2 $\mathrm{mg}$ ) of pale purple crystals. ${ }^{1} \mathrm{H}$ NMR (400 MHz, DMSO-d $\left.{ }_{6}\right): \delta 6.6(\mathrm{~d}, J=9.2 \mathrm{~Hz}, 2 \mathrm{H}), 6.5(\mathrm{~d}, J=9.2 \mathrm{~Hz}, 2 \mathrm{H}), 4.5$ (br s, $2 \mathrm{H}), 3.6(\mathrm{~s}, 3 \mathrm{H}){ }^{8}$

2-Aminotoluene (2c): Purification by flash chromatography (hexane: ethyl acetate $=12: 1)$ gave $81 \%(51.3$ $\mathrm{mg}$ ) of a colorless oil. ${ }^{1} \mathrm{H}$ NMR (400 MHz, DMSO-d 6 ): $\delta 6.7$ (m, 2H), $6.5(\mathrm{~m}, 2 \mathrm{H}), 4.6(\mathrm{br} \mathrm{s}, 2 \mathrm{H}), 3.6(\mathrm{~s}, 3 \mathrm{H}) .{ }^{9}$

4-Aminotoluene (2d): Purification by flash chromatography (hexane: ethyl acetate $=10: 1)$ gave $84 \%$ (44.9 $\mathrm{mg}$ ) of pale yellow crystals. ${ }^{1} \mathrm{H}$ NMR (400 MHz, DMSO-d 6 ): $\delta 6.8$ (d, $\left.J=9.2 \mathrm{~Hz}, 2 \mathrm{H}\right), 6.4(\mathrm{~d}, J=9.2,2 \mathrm{H}), 4.7$ (br $\mathrm{s}, 2 \mathrm{H}), 2.1(\mathrm{~s}, 3 \mathrm{H}){ }^{9}$

1,4-Phenylenediamine (2e): Purification by flash chromatography (hexane: ethyl acetate = 8: 1) gave 62\% (34.5 mg) of purple crystals. ${ }^{1} \mathrm{H}$ NMR (400 MHz, DMSO-d $\left.\mathrm{d}_{6}\right): \delta 6.3(\mathrm{~s}, 4 \mathrm{H}), 4.2(\mathrm{br} \mathrm{s}, 2 \mathrm{H}) .{ }^{10}$

4-Aminophenol (2f): Purification done by flash chromatography (hexane: ethyl acetate = 8: 1) gave 79\% (43.1 mg) of brown solid. ${ }^{1} \mathrm{H}$ NMR (400 MHz, DMSO-d 6 ): $\delta 8.4$ (s, 1H), 6.5 (d, $\left.J=8.8 \mathrm{~Hz}, 2 \mathrm{H}\right), 6.5$ (d, $J=8.8$ $\mathrm{Hz}, 2 \mathrm{H}), 4.4$ (br s, 2H). ${ }^{10}$

4-Trifluromethylaniline (2g): Purification by flash chromatography (hexane: ethyl acetate = 8: 1) gave $66 \%\left(66 \mathrm{mg}\right.$ ) of purple crystals. ${ }^{1} \mathrm{H}$ NMR (400 MHz, DMSO-d 6 ): $\delta 7.3$ (d, J=8.4 Hz, 2H), $6.6(\mathrm{~d}, J=8.4 \mathrm{~Hz}, 2 \mathrm{H})$, 5.8 (br s, $2 \mathrm{H}){ }^{10}$

2-Bromoaniline (2h): Purification by flash chromatography (hexanes: ethyl acetate $=10: 1)$ gave $67 \%(57.6$ $\mathrm{mg}$ ) of pale yellow crystals. ${ }^{1} \mathrm{H}$ NMR (400 MHz, DMSO-d 6 ): $\delta 7.3(\mathrm{dd}, J=8.0,1.4 \mathrm{~Hz}, 1 \mathrm{H}), 7.1-7.0(\mathrm{~m}, 1 \mathrm{H}), 6.8$ (dd, $J=8.0,1.4 \mathrm{~Hz}, 1 \mathrm{H}), 6.5-6.4(\mathrm{~m}, 1 \mathrm{H}), 5.3$ (br s, $2 \mathrm{H}){ }^{11}$

4-Iodoaniline (2i): Purification by flash chromatography (hexane: ethyl acetate $=10: 1)$ gave $69 \%(48.4 \mathrm{mg}$ ) of pale brown crystals, ${ }^{1} \mathrm{H}$ NMR (400 MHz, $\left.\mathrm{CDCl}_{3}\right): \delta 7.43$ (d, J=8.8 Hz, 2H), 6.47 (d, J=8.8 Hz, 2H), 3.70 (br $\mathrm{s}, 2 \mathrm{H}){ }^{12}$

4-Bromoaniline (2j): Purification by flash chromatography (hexane: ethyl acetate $=10: 1)$ gave $75 \%(76.6$ $\mathrm{mg}$ ) of brown solid. ${ }^{1} \mathrm{H}$ NMR (400 MHz, DMSO-d 6 ): $\delta 4.3$ (d, $\left.J=8.8 \mathrm{~Hz}, 2 \mathrm{H}\right), 6.5$ (d, J=8.8 Hz, 2H), 3.6 (br s, $2 \mathrm{H})^{7}$ 
3-chloroaniline (2k): Purification by flash chromatography (hexane: ethyl acetate $=10: 1)$ gave $74 \%(49.7$ $\mathrm{mg}$ ) of pale yellow crystals. ${ }^{1} \mathrm{H}$ NMR (400 MHz, DMSO-d $\left.\mathrm{d}_{6}\right)$ : $\delta$ 7.05-7.01 (m, 1H), 6.62-6.50 (m, 1H), 6.5-6.4 (m, $2 \mathrm{H}), 5.4(\mathrm{br} \mathrm{s}, 2 \mathrm{H}){ }^{13}$

\section{ESR study}

The ESR spectra of the samples were initially recorded using an electron spin resonance spectrometer (JES-X310) with $9.542 \mathrm{GHz}$ microwave frequency, $100 \mathrm{kHz}$ modulation frequency, $1 \mathrm{~mW}$ power, and 2 min of weep time. The samples ( $\sim 1 \mathrm{mg}$ each) were sealed in a 1-mm-internal-diameter, 50-mm-long quartz capillary tubes. Radical contents were calculated from the integration of ESR spectra using TEMPOL (4-hydroxy-2,2,6,6tetramethylpiperidine-1-oxyl) as a standard.

As can be seen from Figure S3a, a pair of broad peaks were observed for NrGO, suggesting the presence of delocalized radical species. Upon the addition of ${ }^{\mathrm{t}} \mathrm{BuOK}$ to $\mathrm{NrGO}$, these peaks became narrower, thus implying that the delocalized radicals on the surface of $\mathrm{NrGO}$ have become localized (Figure S3b)
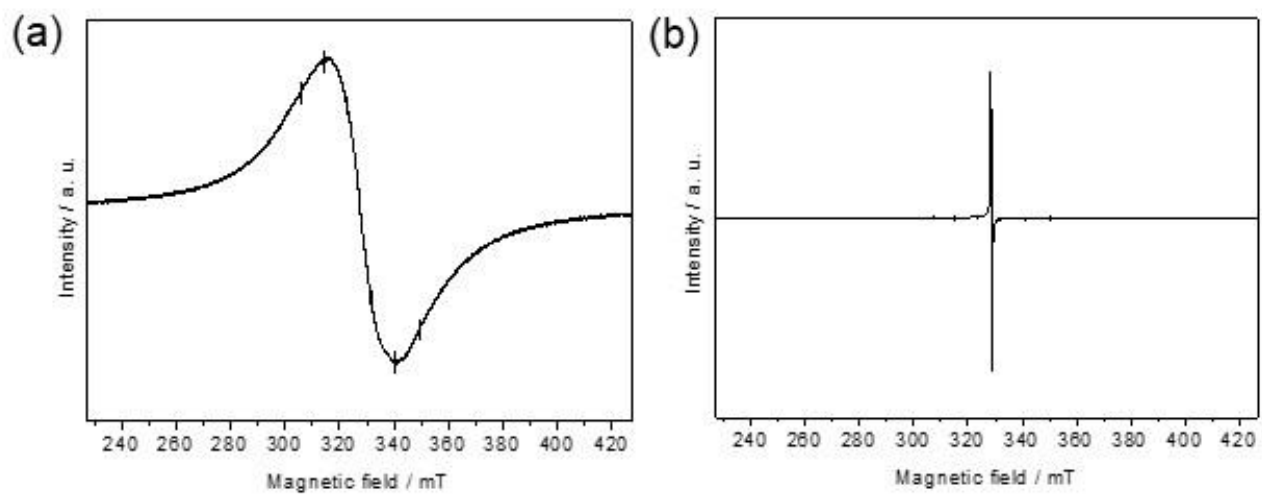

Figure S3. (a) ESR spectrum of NrGO. (b) ESR spectrum of NrGO after mixing with 'BuOK.

\section{Spin trap experiment}

1) $\mathrm{NrGO}(1 \mathrm{mg})$ was placed in an ESR tube, sealed, and analyzed.

2) $\mathrm{NrGO}(10 \mathrm{mg})$ and ${ }^{\mathrm{BuOK}}(0.5 \mathrm{mmol})$ were mixed homogenously, $1 \mathrm{mg}$ of the resulting mixture was immediately transferred to an ESR tube and analyzed.

3) $\mathrm{NrGO}(10 \mathrm{mg})$, IPA (2 mL), and a stir bar were loaded into an autoclave, together with 5,5-dimethyl-1-pyrroline $\mathrm{N}$-oxide (DMPO). The reaction mixture was then stirred at $130^{\circ} \mathrm{C}$. After the completion of the reaction, the liquid mixture was taken and analyzed by ESR.

4) For the hydrogen trapping, the same method was used; while the autoclave was purged with $1.5 \mathrm{MPa} \mathrm{H}_{2}$ before stirring at $130{ }^{\circ} \mathrm{C}$. After releasing the hydrogen pressure, the liquid sample was taken up and directly measured by ESR. 


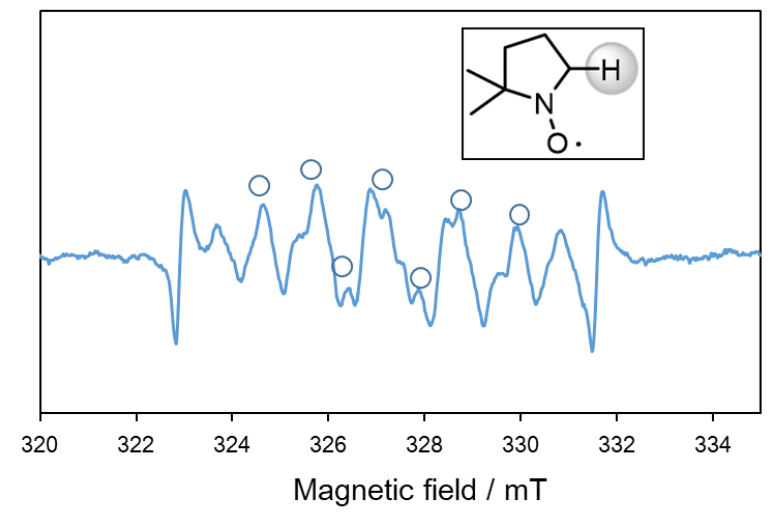

Figure S4. In situ ESR analysis of the mixture of DMPO, $\mathrm{NrGO}$, and ${ }^{\mathrm{t}} \mathrm{BuOK}$ in IPA in the presence of $\mathrm{H}_{2}$.

\section{Method for the recyclability test}

Typically, a mixture of nitrobenzene (0.5 mmol), NrGO (20 mg), ${ }^{\mathrm{t}} \mathrm{BuOK}(1.0 \mathrm{mmol})$, IPA (4 mL), and $\mathrm{H}_{2}$ (1.5 MPa) was loaded into a steel-based autoclave. The mixture was heated to $130{ }^{\circ} \mathrm{C}$ under continuous stirring for $2 \mathrm{~h}$. After the completion of the reaction, the mixture was cooled down to room temperature and filtered. The liquid phase (product) was analyzed by GC. The recovered catalyst was washed with water and then ethanol, and subsequently dried, before its use in the next reaction. The process was repeated up to the fourth cycle, and the yields were calculated by GC. 


\section{Screening test}

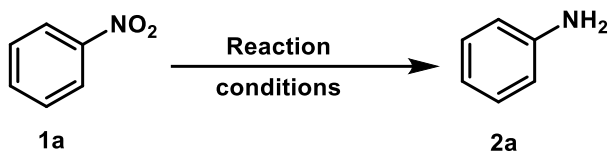

Table S2: Screening results. ${ }^{[a]}$

\begin{tabular}{|c|c|c|c|c|}
\hline Entry & Base & Catalyst & Solvent & $\%$ Yield \\
\hline 1 & -- & $\mathrm{NrGO}$ & DMSO & 14 \\
\hline 2 & tBuOK & --- & DMSO & 11 \\
\hline 3 & 'BuOK & $\mathrm{NrGO}$ & DMSO & 58 \\
\hline 4 & ${ }^{\mathrm{t}} \mathrm{BuOK}$ & $\mathrm{NrGO}$ & IPA & 80 \\
\hline 5 & 'BuOK & $\mathrm{NrGO}$ & THF & 39 \\
\hline 6 & 'BuOK & $\mathrm{NrGO}$ & Toluene & 25 \\
\hline 7 & ${ }^{\mathrm{t}} \mathrm{BuOK}$ & $\mathrm{NrGO}$ & Ethanol & 46 \\
\hline 8 & ${ }^{\mathrm{t}} \mathrm{BuOK}$ & $\mathrm{NrGO}$ & 1,4-dioxane & 15 \\
\hline 9 & ${ }^{\mathrm{t}} \mathrm{BuOK}$ & $\mathrm{NrGO}$ & Water & 0 \\
\hline 10 & ${ }^{\mathrm{t}} \mathrm{BuOK}$ & NrGO & Pyridine & 10 \\
\hline 11 & ${ }^{\mathrm{t}} \mathrm{BuOK}$ & $\mathrm{NrGO}$ & Acetonitrile & 15 \\
\hline 12 & ${ }^{t} \mathrm{BuOK}$ & $\mathrm{NrGO}$ & NMP & 12 \\
\hline 13 & $\mathrm{NaOH}$ & $\mathrm{NrGO}$ & DMSO & 26 \\
\hline 14 & ${ }^{t} \mathrm{BuONa}$ & NrGO & DMSO & 17 \\
\hline 15 & $\mathrm{~K}_{2} \mathrm{CO}_{3}$ & $\mathrm{NrGO}$ & IPA & 30 \\
\hline 16 & $\mathrm{Na}_{2} \mathrm{CO}_{3}$ & NrGO & IPA & 12 \\
\hline 17 & $\mathrm{CsCO}_{3}$ & $\mathrm{NrGO}$ & IPA & 0 \\
\hline 18 & ${ }^{\mathrm{t}} \mathrm{BuOK}$ & $\mathrm{NrGO}$ & IPA & $30^{[\mathrm{b}]}$ \\
\hline
\end{tabular}

[a] Reaction conditions: nitrobenzene $(0.5 \mathrm{mmol}),{ }^{\mathrm{t}} \mathrm{BuOK}(1 \mathrm{mmol}), \mathrm{NrGO}(20 \mathrm{mg}), 2 \mathrm{~h}, 130{ }^{\circ} \mathrm{C}, \mathrm{H}_{2}(1.5 \mathrm{MPa})$. Yields were determined by GC using dodecane as an internal standard. ${ }^{[\mathrm{b}]}$ The reaction was performed without molecular hydrogen. 


\section{Proposed reaction pathway}

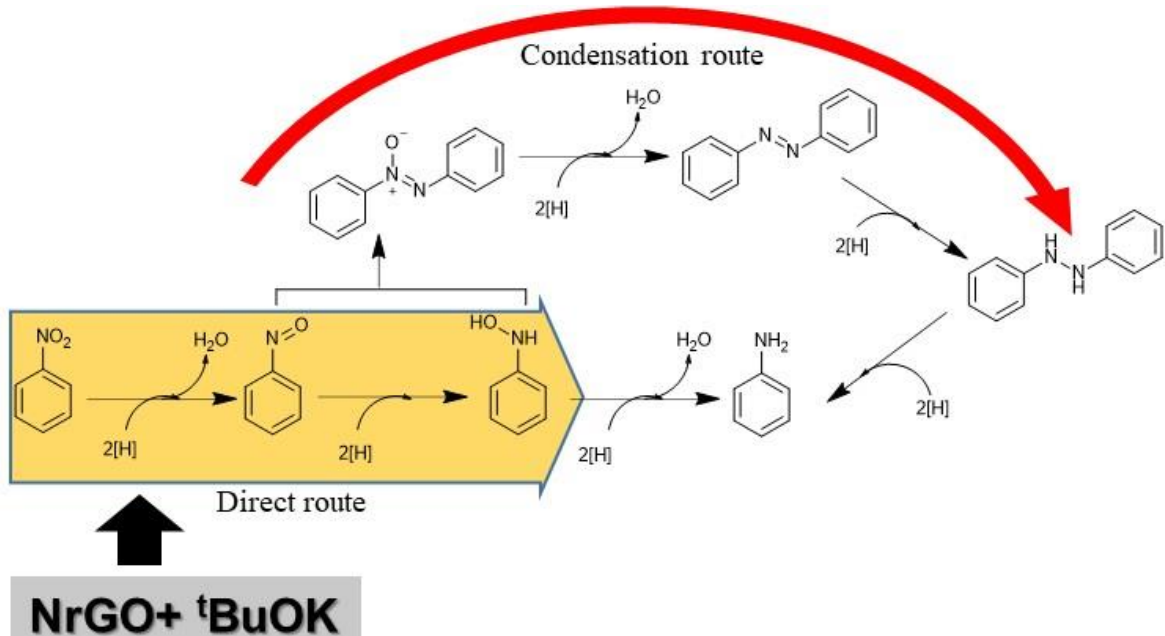

Scheme S2: Different mechanisms for the hydrogenation reaction of nitrobenzene to aniline, catalyzed by NrGO.

\section{Recyclability of the catalyst}

XPS analysis at $\mathrm{C} 1 \mathrm{~s}$ region of $\mathrm{GO}$ before and after the hydrogenation reaction indicated a drastic decrease of $\mathrm{C}-\mathrm{O} / \mathrm{C}=\mathrm{O}$ on the surface (Figure S5). In contrast, $\mathrm{NrGO}$ did not change before and after the reaction (Figure S7).
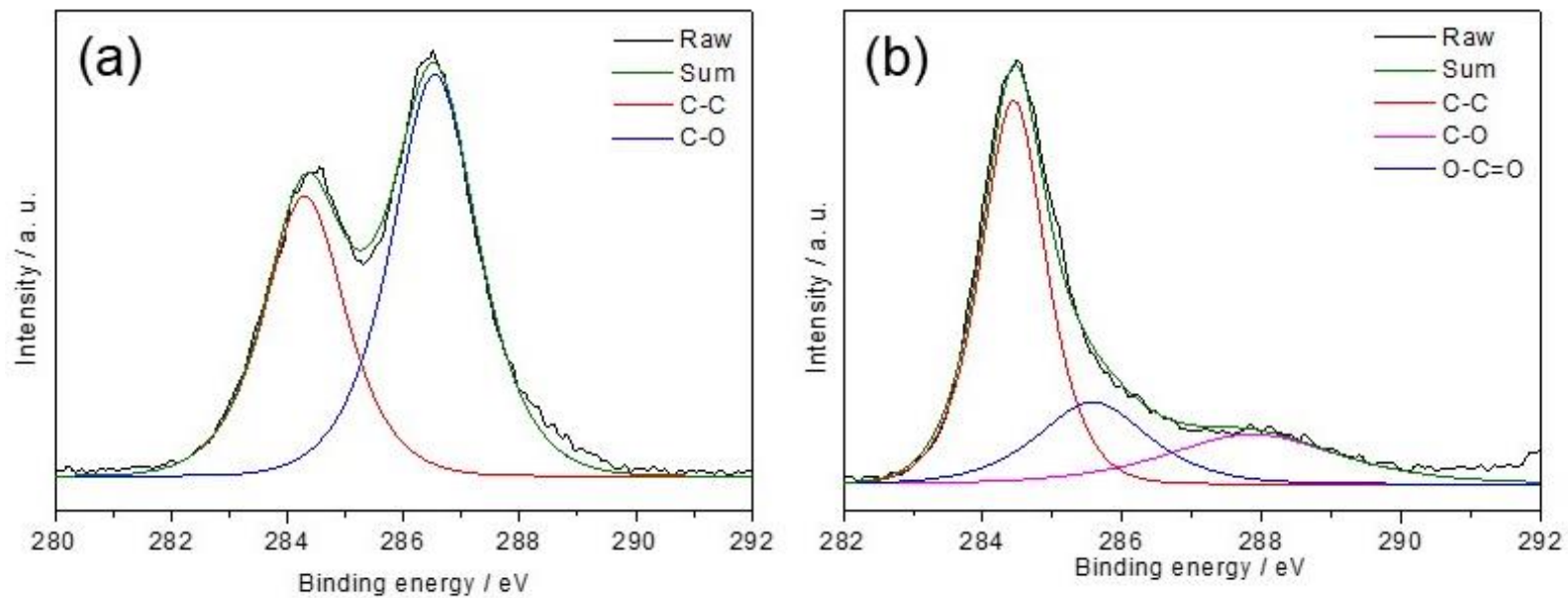

Figure S5: XPS C 1s of GO (a) before and (b) after the hydrogenation reaction. 

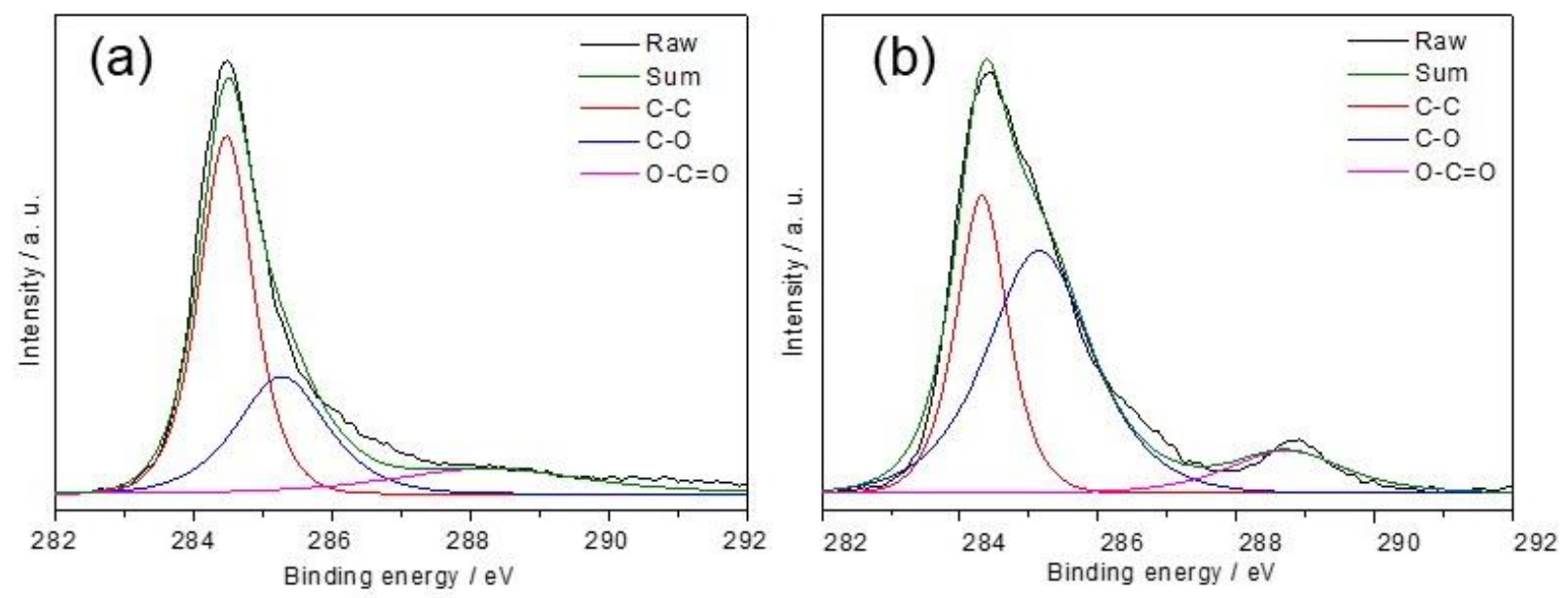

Figure S6: XPS C 1s of rGO (a) before and (b) after the reaction.
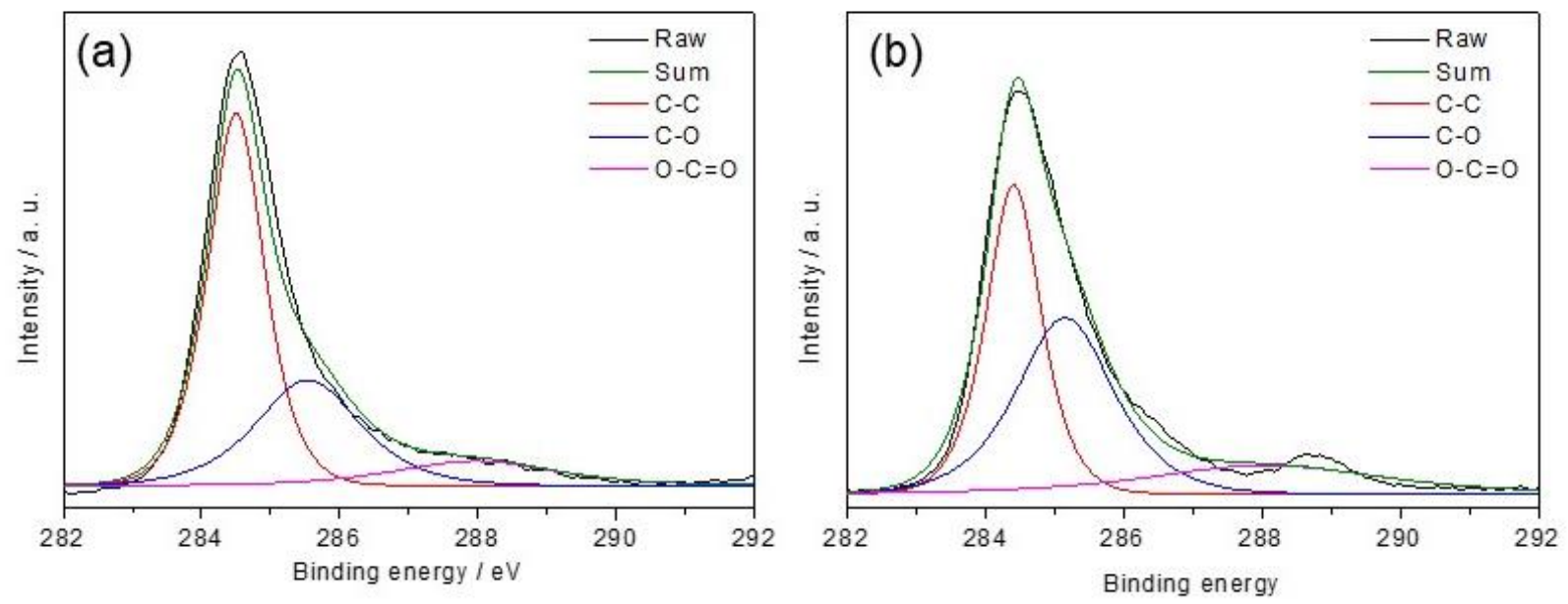

Figure S7: XPS C 1s of NrGO (a) before and (b) after the reaction. 

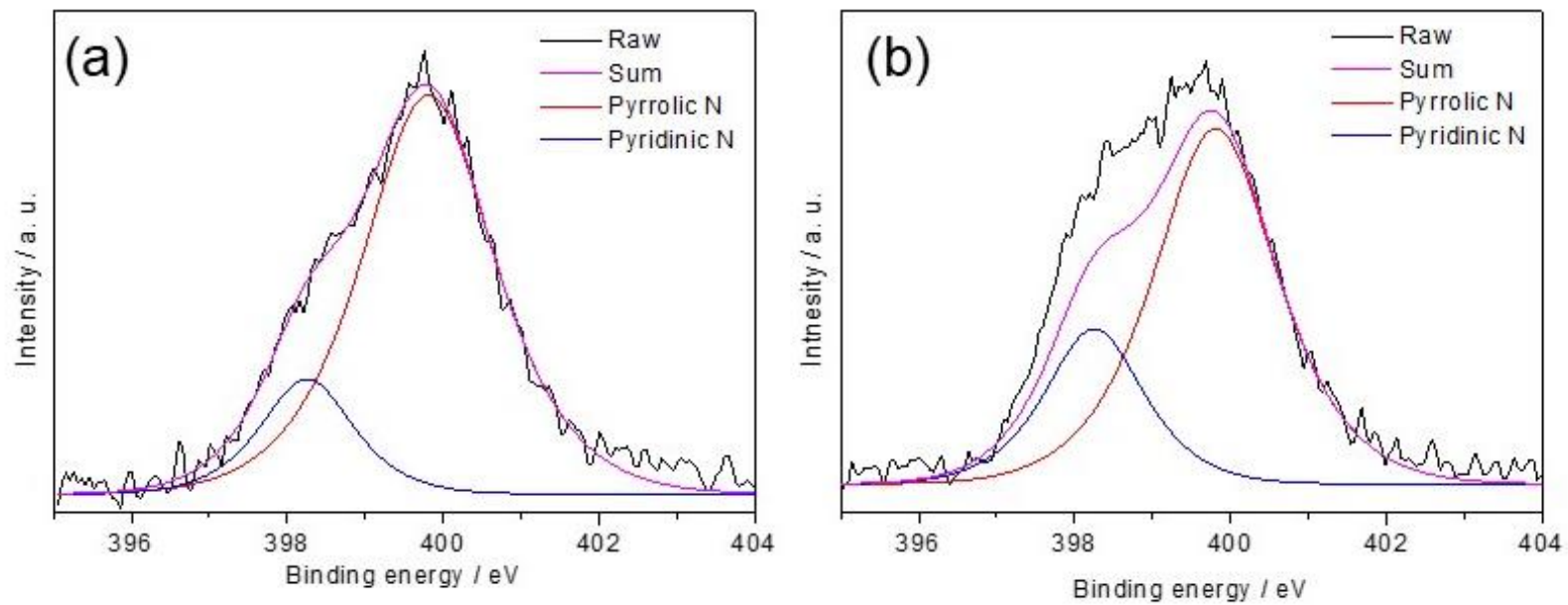

Figure S8: XPS spectra of $\mathrm{N} 1 \mathrm{~s}$ of $\mathrm{NrGO}$ (a) before and (b) after the reaction.

\section{6. ${ }^{1} \mathrm{H}$ NMR spectral charts of the Aniline derivatives}

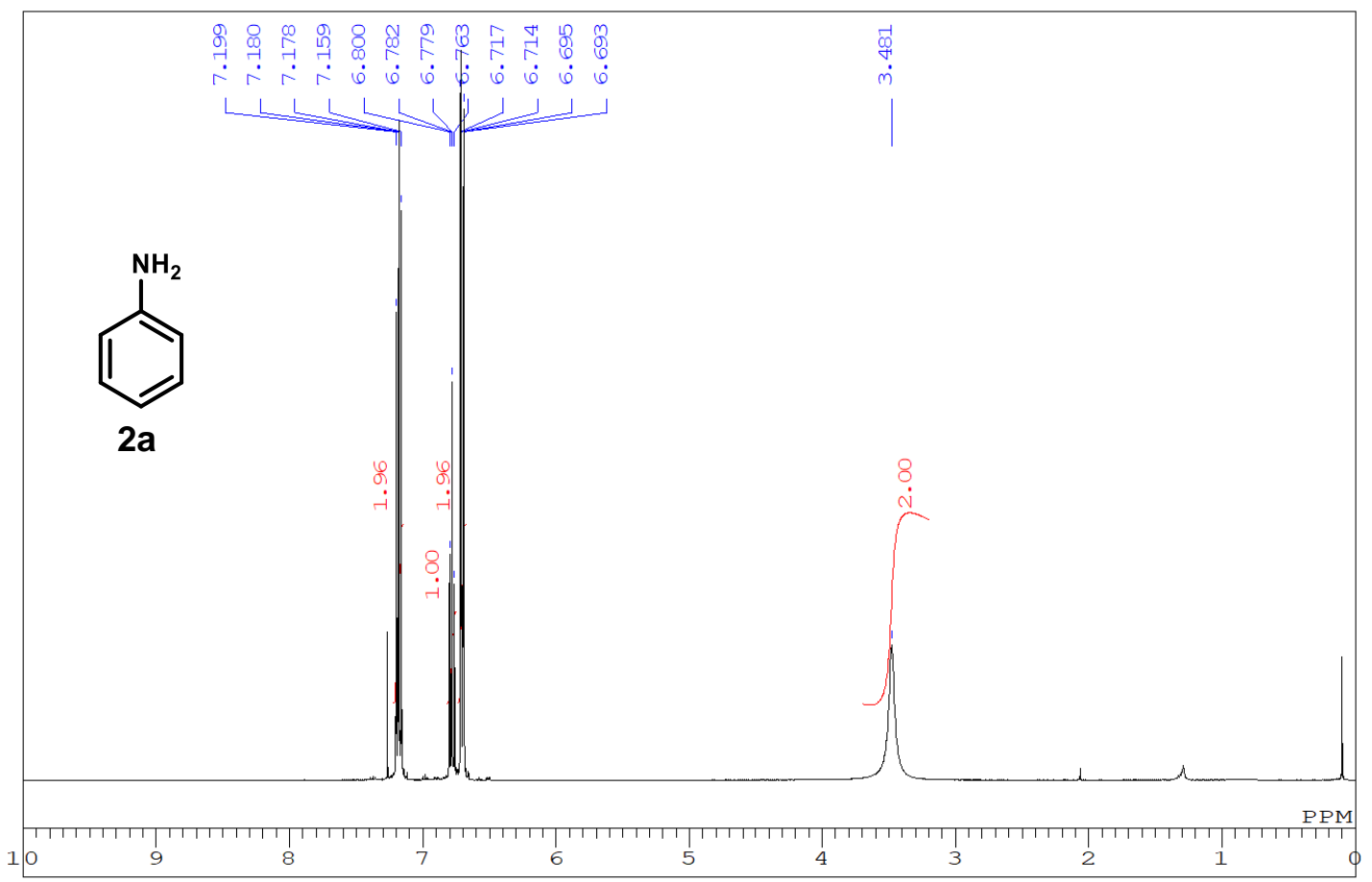



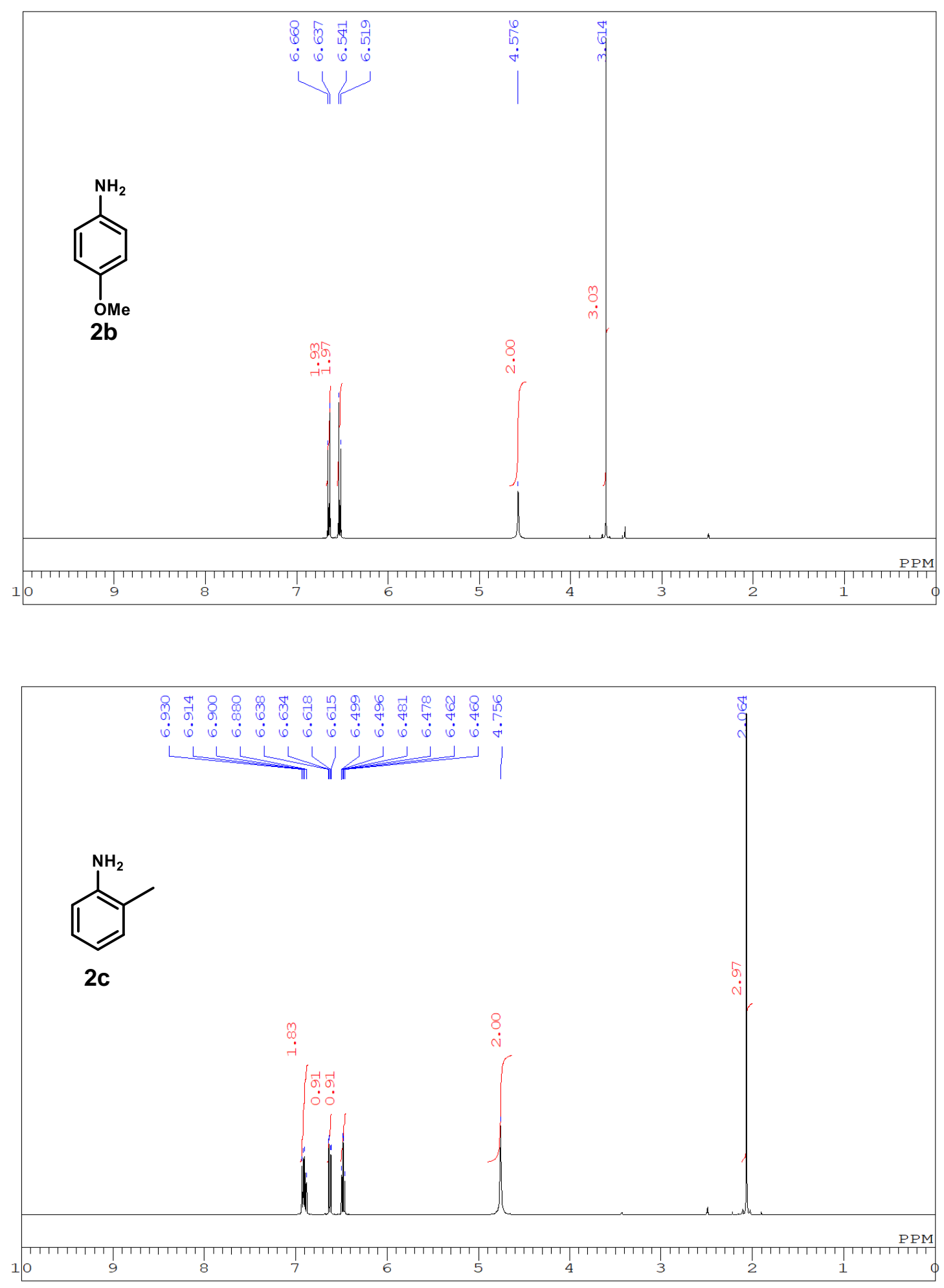

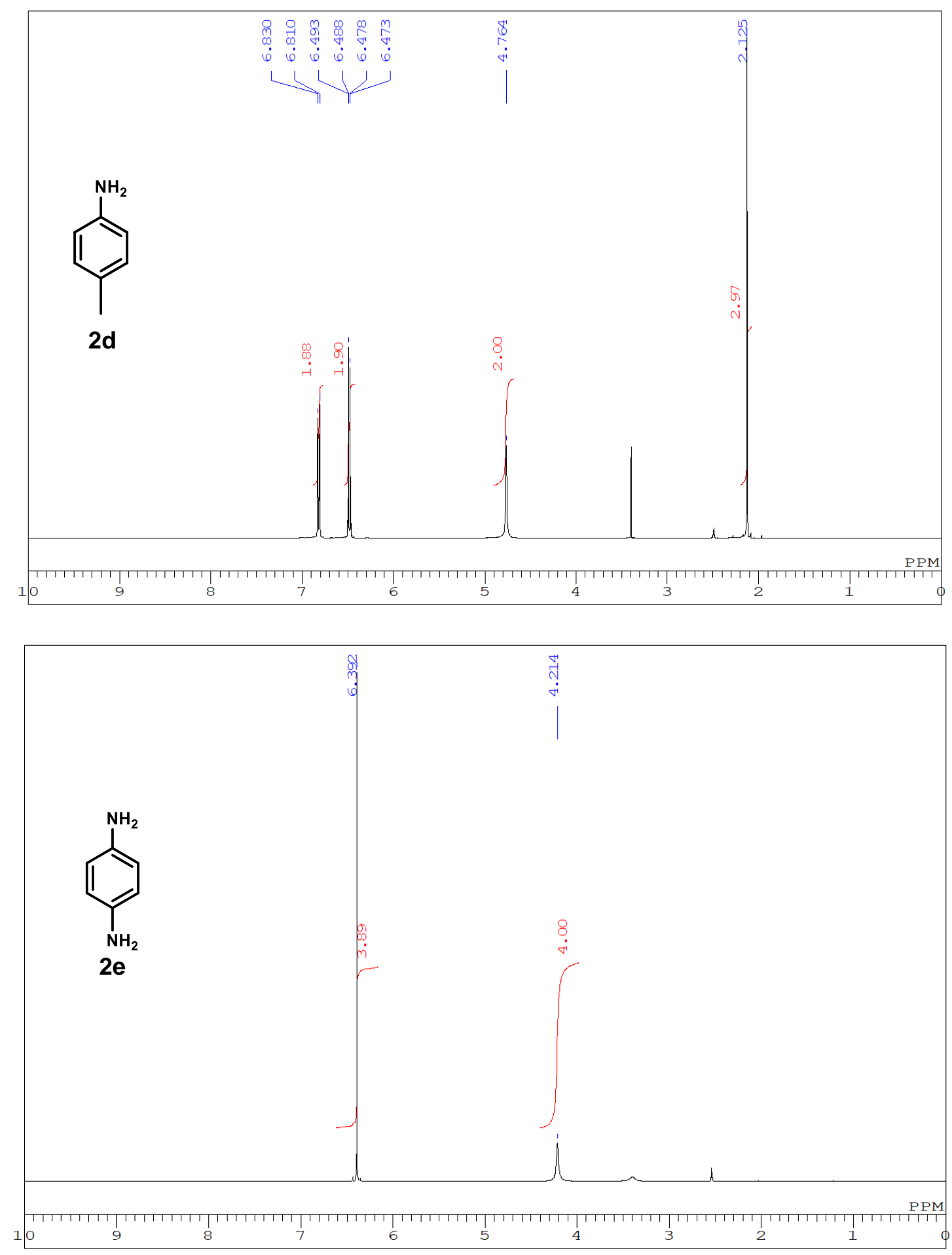

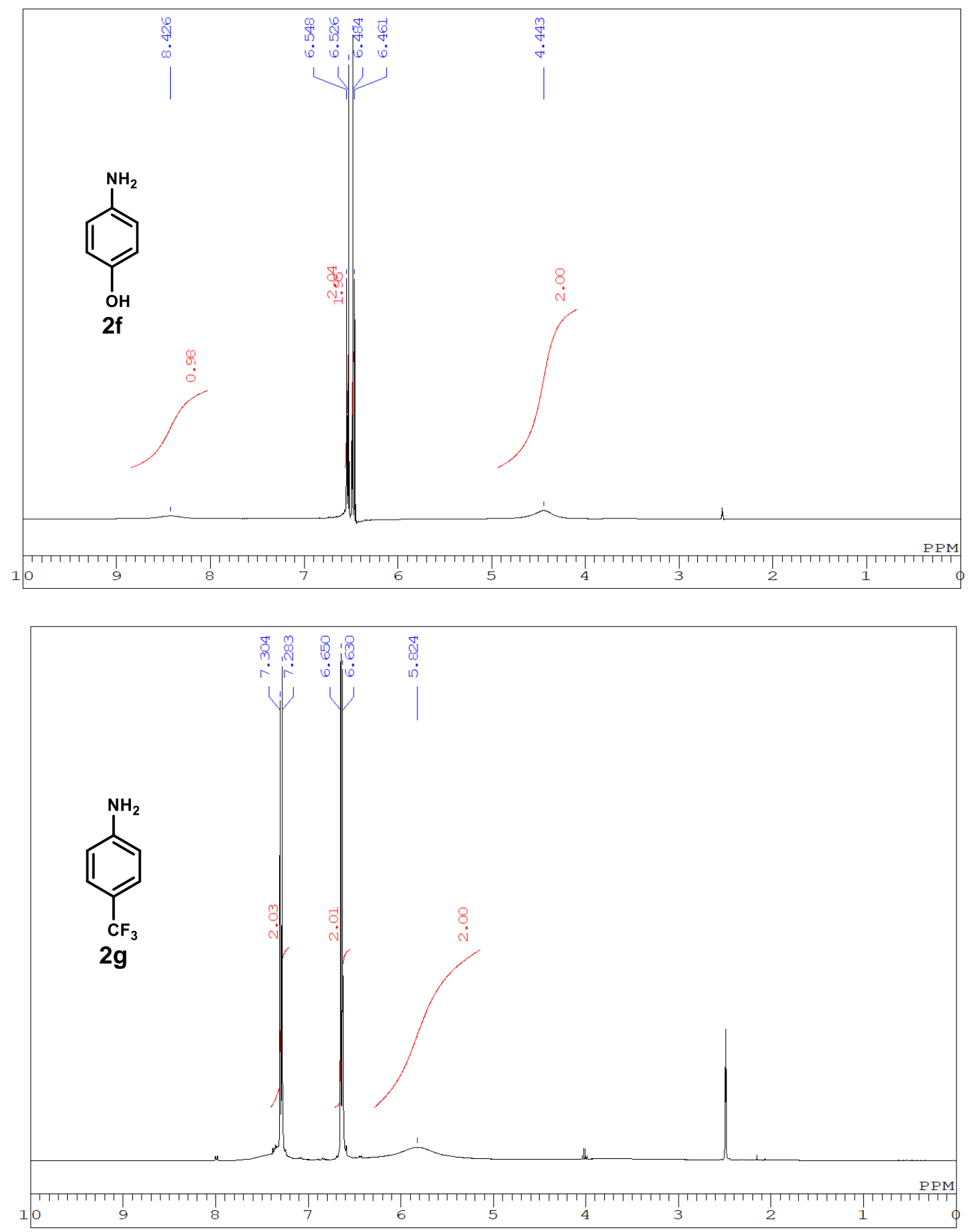

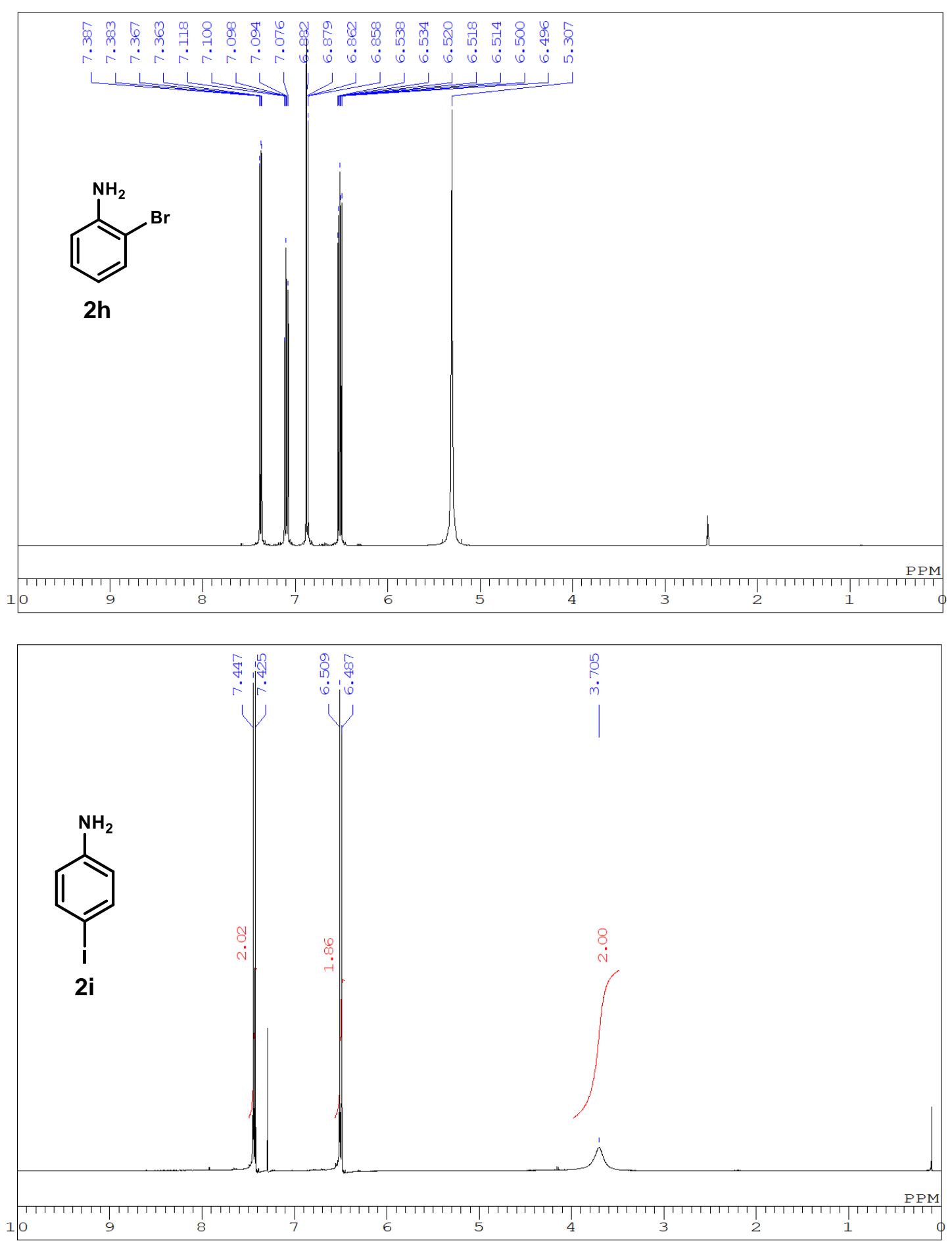

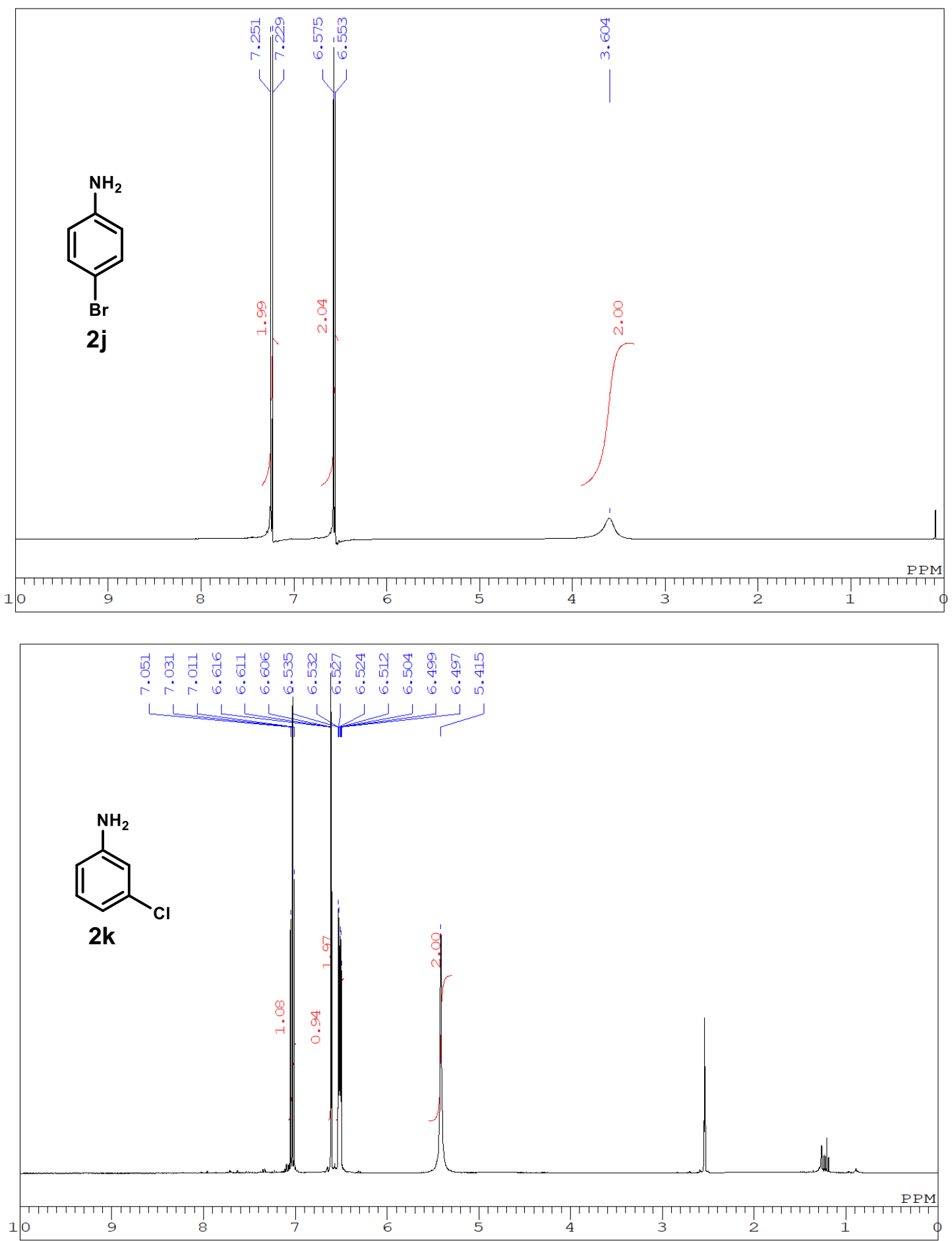

\section{GC-MS data for prodcuts $4 a, 4 b, 4 c, 6$, and 9}

Hydrogenation of ketones, and substituted nitrobenzene were performed in $30 \mathrm{ml}$ of stainless autoclave fitted with an inner glass tube. Upon completion of reaction run, the catalyst $(\mathrm{NrGO})$ was removed by filtration, and the filtrate was extracted with ethyl acetate. The solvent were evaporated via rotary evaporator. All of these compounds are known compounds, purification by flash chromatography using (hexane/ethyl acetate) as eluent, these results were in accordance with the reported literature. 
1-phenylethanol (4a) ${ }^{14}$ : The desire product was colorless oil in $(41.4 \mathrm{mg}, 71 \%)$.
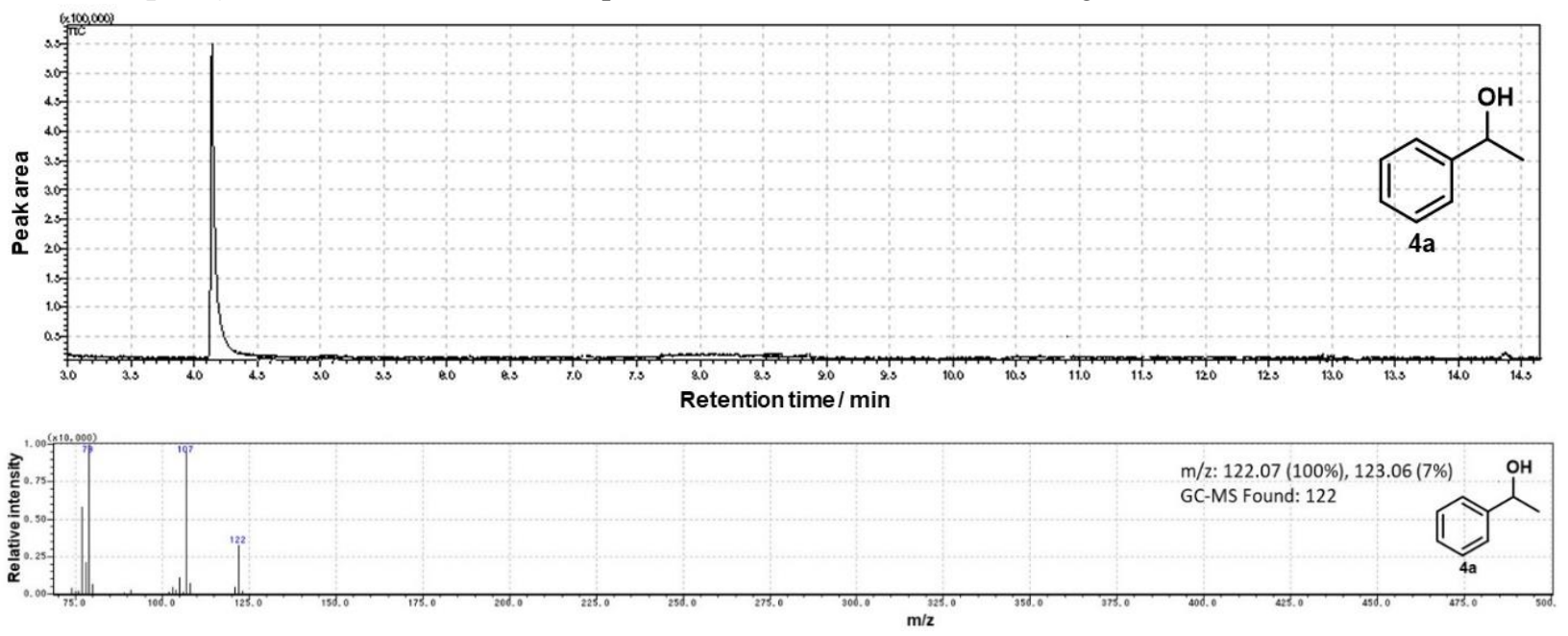

1-(4-bromophenyl)ethanol (4b) ${ }^{14}$ : The target product was obtained as white crystal $(66.2 \mathrm{mg}, 67 \%)$.
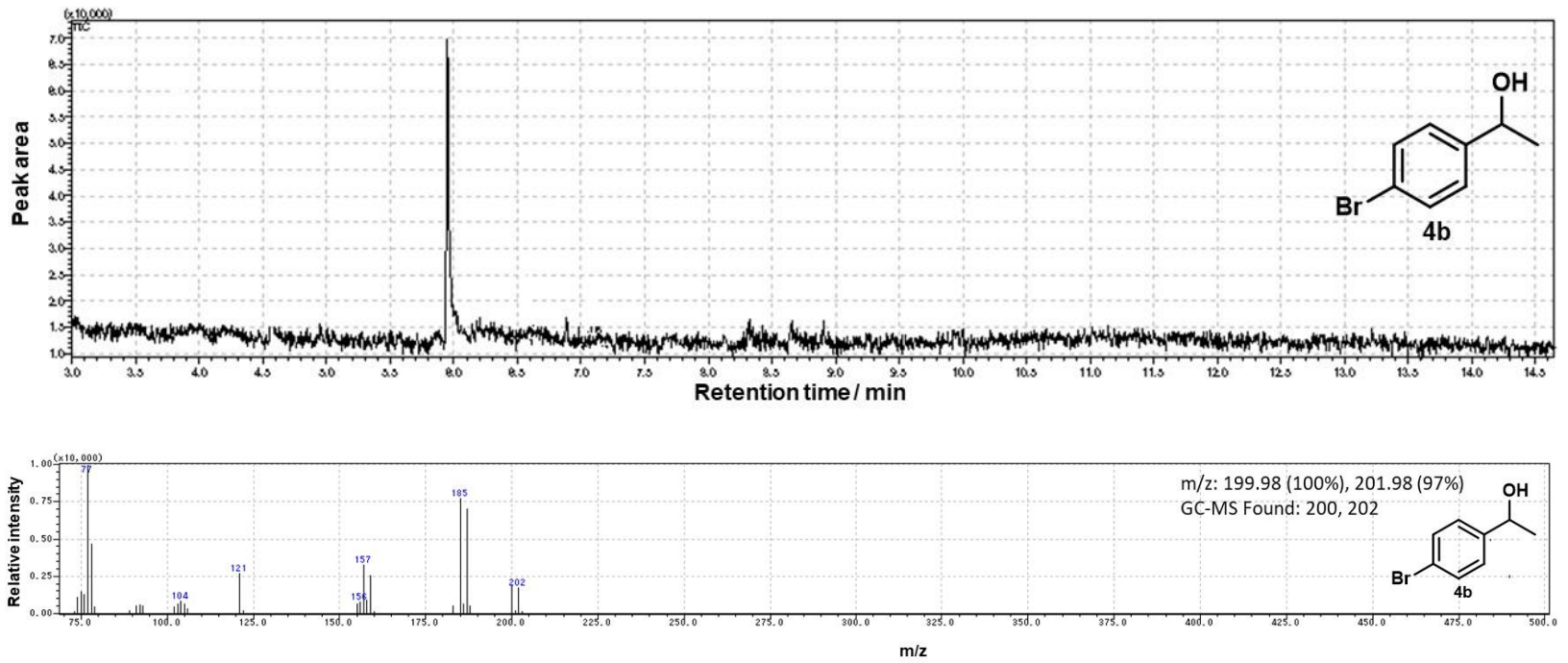

1-(4-chlorophenyl)ethanol (4c) ${ }^{14}$ : The desire product was collected as colorless liquid (50.2 mg, 65\%). 

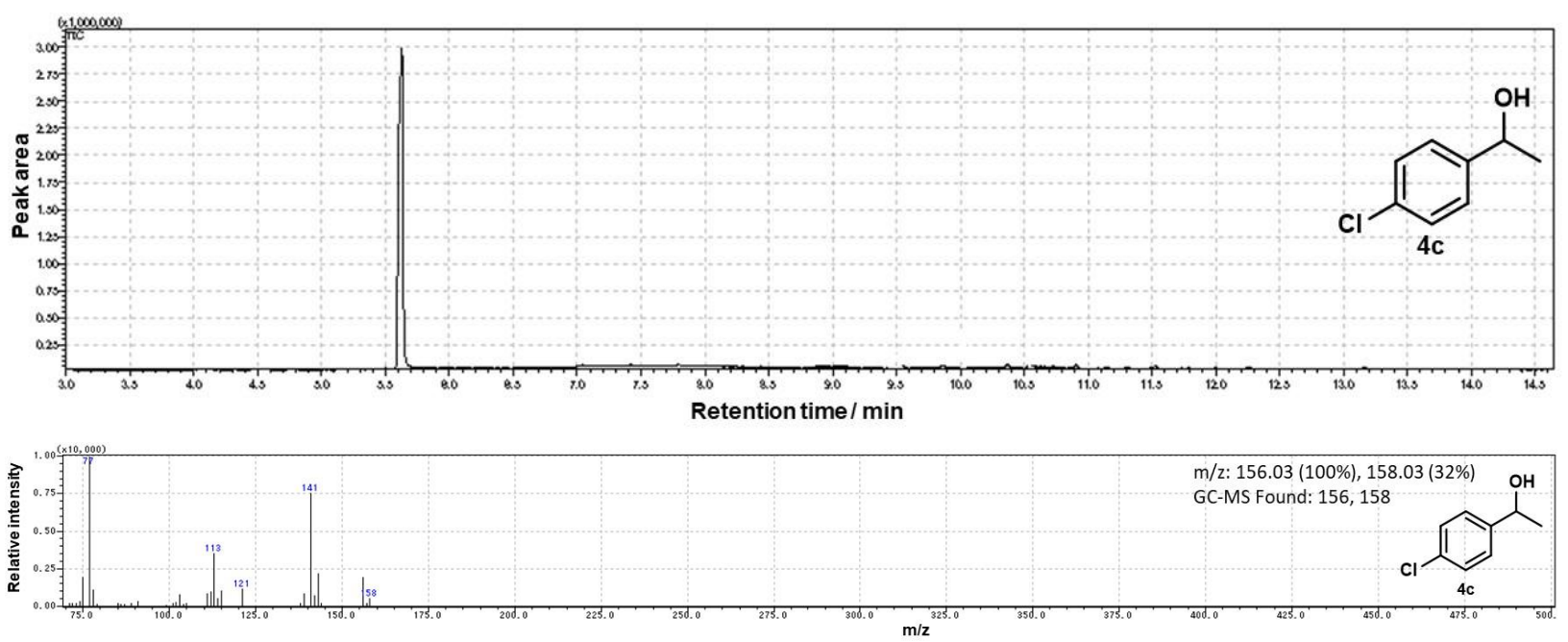

4-(4-ethynylphenyl)aniline (6) ${ }^{15}$ : The desire product 6 were obtained solid in white color $(73.1 \mathrm{mg}, 65 \%)$.
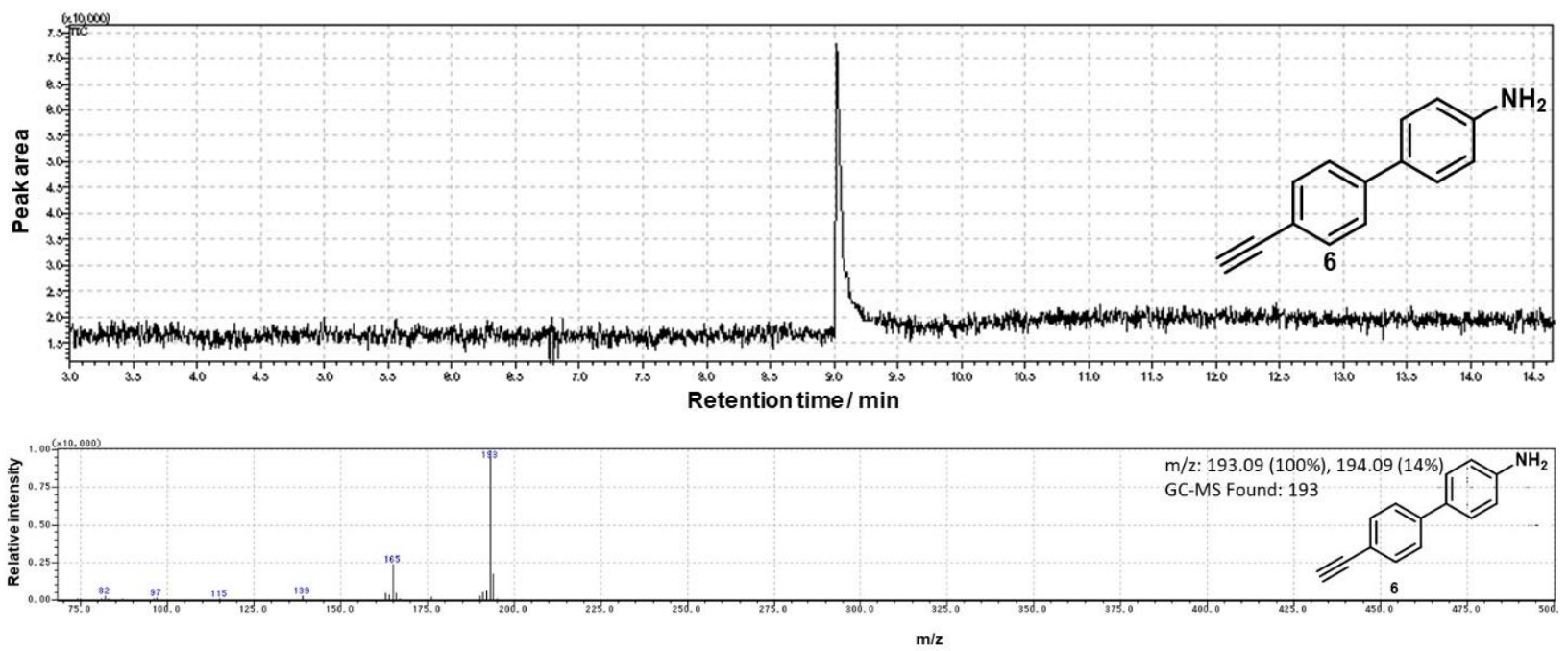

Aminoacetophenone (9) ${ }^{16}$ : The product 9 were collected in yellow crystal $(65.5 \mathrm{mg}, 68 \%)$.
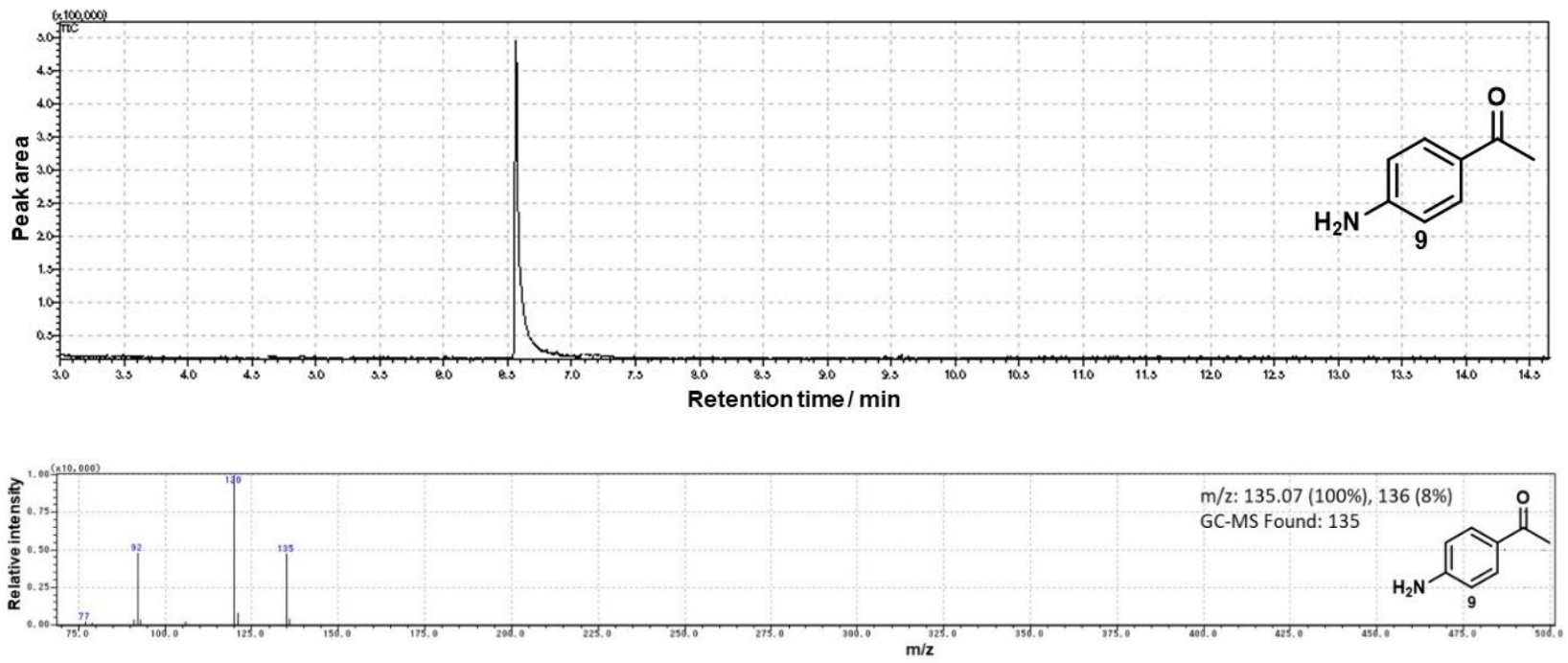


\section{References}

(1) Senthilnathan, J.; Rao, K. S.; Yoshimura, M. Submerged Liquid Plasma-Low Energy Synthesis of Nitrogen-Doped Graphene for Electrochemical Applications. J. Mater. Chem. A 2014, 2 (10), 3332 3337.

(2) Chua, C. K.; Pumera, M. Reduction of Graphene Oxide with Substituted Borohydrides. J. Mater. Chem. A 2013, 1 (5), 1892-1898.

(3) Zhang, Y.; Sun, Z.; Wang, H.; Wang, Y.; Liang, M.; Xue, S. Nitrogen-Doped Graphene as a Cathode Material for Dye-Sensitized Solar Cells: Effects of Hydrothermal Reaction and Annealing on Electrocatalytic Performance. RSC Adv. 2015, 5 (14), 10430-10439.

(4) Kumar, M. P.; Kesavan, T.; Kalita, G.; Ragupathy, P.; Narayanan, T. N.; Pattanayak, D. K. On the Large Capacitance of Nitrogen Doped Graphene Derived by a Facile Route. RSC Adv. 2014, 4 (73), 3868938697.

(5) Nolan, H.; Mendoza-Sanchez, B.; Kumar, N. A.; McEvoy, N.; O’Brien, S.; Nicolosi, V.; Duesberg, G. S. Nitrogen-Doped Reduced Graphene Oxide Electrodes for Electrochemical Supercapacitors. Phys. Chem. Chem. Phys. 2014, 16 (6), 2280-2284.

(6) Gao, Y.; Tang, P.; Zhou, H.; Zhang, W.; Yang, H.; Yan, N.; Hu, G.; Mei, D.; Wang, J.; Ma, D. Graphene Oxide Catalyzed C-H Bond Activation: The Importance of Oxygen Functional Groups for Biaryl Construction. Angew. Chem. Int. Ed. 2016, 55 (9), 3124-3128. https://doi.org/10.1002/anie.201510081.

(7) Vijaykumar, G.; Mandal, S. K. An Abnormal N-Heterocyclic Carbene Based Nickel Complex for Catalytic Reduction of Nitroarenes. Dalton Trans. 2016, 45 (17), 7421-7426. https://doi.org/10.1039/C6DT00470A.

(8) Xu, H.; Wolf, C. Efficient Copper-Catalyzed Coupling of Aryl Chlorides, Bromides and Iodides with Aqueous Ammonia. Chem. Commun. 2009, No. 21, 3035. https://doi.org/10.1039/b904188e.

(9) Vernekar, A. A.; Patil, S.; Bhat, C.; Tilve, S. G. Magnetically Recoverable Catalytic Co-Co2B Nanocomposites for the Chemoselective Reduction of Aromatic Nitro Compounds. RSC Adv. 2013, 3 (32), 13243. https://doi.org/10.1039/c3ra41090k.

(10) Rahaim, R. J.; Maleczka, R. E. Pd-Catalyzed Silicon Hydride Reductions of Aromatic and Aliphatic Nitro Groups. Org. Lett. 2005, 7 (22), 5087-5090. https://doi.org/10.1021/ol052120n.

(11) Kumaran, E.; Sridevi, V. S.; Leong, W. K. Orthometalated Amino-Carbene Derivatives of Iridium via Anilines and Terminal Alkynes. Organometallics 2010, 29 (23), 6417-6421. https://doi.org/10.1021/om100803g.

(12) Yasuhara, A.; Kasano, A.; Sakamoto, T. Convenient Reduction of Nitrobenzenes to Anilines Using Electrochemically Generated Nickel. J. Org. Chem. 1999, 64 (7), 2301-2303. https://doi.org/10.1021/jo981935p.

(13) Takasaki, M.; Motoyama, Y.; Higashi, K.; Yoon, S.-H.; Mochida, I.; Nagashima, H. Chemoselective Hydrogenation of Nitroarenes with Carbon Nanofiber-Supported Platinum and Palladium Nanoparticles. Org. Lett. 2008, 10 (8), 1601-1604. https://doi.org/10.1021/ol800277a.

(14) Westerhaus, F. A.; Jagadeesh, R. V.; Wienhöfer, G.; Pohl, M.-M.; Radnik, J.; Surkus, A.-E.; Rabeah, J.; Junge, K.; Junge, H.; Nielsen, M.; et al. Heterogenized Cobalt Oxide Catalysts for Nitroarene Reduction by Pyrolysis of Molecularly Defined Complexes. Nat. Chem. 2013, 5 (6), 537-543. https://doi.org/10.1038/nchem.1645.

(15) Ding, Z.-C.; Li, C.-Y.; Chen, J.-J.; Zeng, J.-H.; Tang, H.-T.; Ding, Y.-J.; Zhan, Z.-P. Palladium/Phosphorus-Doped Porous Organic Polymer as Recyclable Chemoselective and Efficient Hydrogenation Catalyst under Ambient Conditions. Adv. Synth. Catal. 2017, 359 (13), 2280-2287. https://doi.org/10.1002/adsc.201700374.

(16) Udumula, V.; Tyler, J. H.; Davis, D. A.; Wang, H.; Linford, M. R.; Minson, P. S.; Michaelis, D. J. Dual Optimization Approach to Bimetallic Nanoparticle Catalysis: Impact of M1/M2 Ratio and Supporting Polymer Structure on Reactivity. ACS Catal. 2015, 5 (6), 3457-3462. https://doi.org/10.1021/acscatal.5b00830. 